\title{
Uma Educação Infantil ainda por inventar
}

\section{An early childhood education to be invented}

José Cavalhero, graduado e licenciado em Artes Plásticas, foi professor de diversas escolas públicas e privadas e coordenador pedagógico de artes. Atualmente é mestrando em Psicologia Clínica na PUC-SP e trabalha como assessor pedagógico da Educação Infantil na Escola Vera Cruz e como assessor de arte na Escola Viva, ambas em São Paulo.

Contato: jcavalheroj@gmail.com

\section{Resumo}

Neste artigo, serão discutidos os valores e a cultura da infância em diálogo com os princípios éticos, estéticos e políticos na Educação Infantil, considerando a criança, em suas experienciações, como autora das descobertas e inventividade de mundo, construtora de subjetividades e capaz de conviver com diferentes pontos de vista. Isso empreende uma postura relacional e investigativa da e na prática por parte do adulto, num exercício para lidar com as singularidades, com as subjetividades de todos os envolvidos - adultos e crianças -, o que significa depararse com as incertezas e imprevisibilidades que emergem a partir de um estado de processualidade das aprendizagens e transformar toda essa experiência em referencial para práticas educativas.

Palavras-chave: valores, processualidade, subjetividade, cartografia, poiesis.

\section{Abstract}

The purpose of this paper is to discuss childhood values and culture through several Child Education principles such as ethics, aesthetics and educational guidelines. Ideally, children should play an active role by experiencing their 
findings, exploring their creativity and the surrounding environment; they should be inserted into a context that enables them to accept different points of view. All adults involved in this process should have a relationship-based approach as well as an investigative approach that take singularities of both children and adult and all subjectivity involved in this relation. It is important to keep in mind that uncertainty and unpredictable issues may arise; however, they are part of the learning process and can promote a real educational experience.

Keywords: values, learning process, subjectivity, cartography, poiesis.

\section{Cara Mada}

A cada encontro com você me sentia convidado a desencontrar-me. E esses deliciosos desencontros me provocaram deslocamentos em busca de novos posicionamentos diante da velha e sabida paisagem da educação. Foi nesse jogo de encontros-desencontros-posicionamentos que pude me relacionar com essa mesma paisagem desde outros pontos de vista, por um olhar reticular, quero dizer, um olhar que se constitui por meio de um sistema semelhante ao da produção gráfica. Olhar que se faz pelas tramas de valores conhecidos e, ao mesmo tempo, por tantas outras que surgem diante de novos e possíveis deslocamentos. A questão é que, com esse olhar, criou-se em mim uma imagem de precisão difusa da paisagem educativa, reunindo diferentes concepções que compõem plasticamente um quadro de singularidades a ser apreciado pelo rigor dialógico e democrático...

0 trecho acima pertence à carta que escrevi ao término de uma série de encontros com Madalena Freire. Nele, procuro expressar metaforicamente a complexidade que envolve a experiência de aprendizagem que se constrói num incessante movimento entre rever saberes e se haver com saberes constituídos pelos afetos. Meu desejo, com a escrita deste artigo, é poder continuar a composição daquela transdisciplinar paisagem educativa de precisão difusa - e iniciada num tempo impreciso -, mesclando referências teóricas, impressões de um fazer artístico, teorização das práticas exercidas em formação continuada de profissionais da Educação Infantil e daqueles que atuam no campo da Arte. Ou seja, criar uma narrativa que reúne os olhares de artista-educadorformador-aprendiz, produzindo-me como sujeito de todas essas experiências em conectividade, e que traz, por escolha, ou assunto a ser debatido, situações que problematizam o movimento de uma 
trajetória formativa na produção de subjetividade nas práticas consolidadas, nas inovadoras e naquelas ainda por criar. E isso implica adentrar questões que envolvem princípios e valores.

Uma das principais referências que me movimentam em direção a esse assunto é a abordagem educativa da cidade de Reg'gio Emilia, na Itália', com a qual tive meu primeiro contato em 2002, quando se realizou, na cidade de São Paulo, a exposição As Cem Linguagens da Criança - uma mostra itinerante das práticas educativas com crianças reggianas de 0 a 6 anos. Desde então, sempre que me aproximo como investigador dessa abordagem entendo cada vez mais a importância de estabelecer diálogos entre as dimensões micro e macropolítica para fazer educação pautada em valores, e não em conteúdos. Esses diálogos interdimensionais trazem indagações, inquietações, problematizações sobre o contemporâneo na perspectiva da cultura local e mundial, debatidas dentro e fora das creches e das escolas, envolvendo diretamente uma escuta que se dá entre crianças, adultos e contexto socia².

Nesse trânsito de encontros das escutas, das relações e seus agenciamentos é que se inventam uma pedagogia investigativa e seus modos de produzir subjetividade singular e plural. Quer dizer, trata-se de pensar a educação pelo movimento que se dá num "campo de implicações cruzadas, estando necessariamente determinado neste jogo de forças: valores, interesses, expectativas, compromissos, desejos, crenças, etc." (PASSOS; KASTRUP; ESCÓSSIA, 2003, p. 19).

\section{Ética e estética na educação de implicações cruzadas}

Ao se defender a educação como direito das crianças, por exemplo, pressupõe-se que essa defesa esteja baseada em princípios que, por sua vez, refletem valores projetados num referencial de infância, de comunidade, de sociedade, de cultura. Então, antes mesmo de falarmos em direito, é importante trazer para o debate qual é a imagem de criança que se projeta e de que modo ela determina os valores em relação ao ensino e à aprendizagem de meninos e meninas. As práticas educativas, sejam quais forem, exercidas numa determinada instituição escolar, estão alicerçadas em um feixe de princípios e valores, ou no jogo de forças que fundamenta uma ética e uma estética institucional.

Valendo-me de uma ideia cara a Gilles Deleuze - de que a ética é estar à altura daquilo que nos acontece -, penso que podemos
1. "A Abordagem Reggio Emilia é uma filosofia educacional baseada na imagem da criança e dos seres humanos como portadores de fortes potencialidades de desenvolvimento e como sujeitos de direito que aprendem e crescem na relação com os outros. Este projeto educativo global é desenvolvido em creches e pré-escolas municipais de Reggio Emilia, na Itália, e tem inspirado escolas em todo o mundo. Fundamenta-se em uma série de características singulares, tais como: a participação das famílias, o trabalho em colegiado com toda a equipe, a importância do ambiente educacional, a presença do ateliê e da figura do atelierista, a cozinha interna, e a coordenação pedagógica e didática. Concentrando-se nas "cem linguagens" pertencentes a cada ser humano, os espaços de ateliê oferecem, quotidianamente, para as crianças, oportunidades de encontrar muitos tipos de materiais, linguagens expressivas, pontos de vista, trabalhando ativa e concomitantemente com as mãos, mentes e emoções, em um contexto que valoriza a expressividade e criatividade de cada criança e delas no grupo." (Reggio Children Identity, tradução minha). 0 original se encontra disponível em: <http://www. reggiochildren.it/identita/reggio=-emilia-approach/? langen>. Acesso em: 10 nov. 2015.

2. Para saber mais, consulte o site disponível em: <http:// www.scuolenidi.re.it/>. Acesso em: 10 nov. 2015. 
adentrar o exercício ético em relação ao direito à educação sob duas perspectivas. A primeira diz respeito à garantia do desenvolvimento cognitivo da criança rumo ao mundo adulto, cuja responsabilidade para o cumprimento desse direito é atribuída exclusivamente às instituições escolares e/ou políticas públicas, delegando para um grupo de especialistas - do qual os pais não participam - a gestão de proposições homogêneas com o intuito de suprir o déficit de cognição da criança. Para controlar esse procedimento, é preciso certificar-se de que categorias como inexistência de pensamento, ausência de função simbólica, irreversibilidade das formas, inteligência pré-operatória, pré-lógica, etc. sejam identificadas e, portanto, superadas evolutivamente (KASTRUP, 2007).

Esse panorama pressupõe que os pais certifiquem-se de que seus filhos sejam atendidos por esse sistema de ensino que adota a disciplinarização como meio, e de que as escolas - e/ou governos - comprovem o cumprimento de seus deveres, avaliando, por meio de métodos quantitativos, o controle sobre o desenvolvimento da criança e a regulagem de suas aprendizagens. Em outras palavras, é direito do meu filho aprender aquilo que a escola se propõe a ensiná-lo; é dever da escola fazer com que todos os alunos aprendam o que é preciso ensinar. A questão é formar indivíduos disciplinados num esforço de equipá-los "com as habilidades e com os valores culturais dominantes que já estão determinados, socialmente sancionados e prontos para serem administrados" (DAHLBERG; MOSS; PENCE, 2003, p. 65) para que, na vida adulta, especializem-se em uma determinada área do conhecimento objetivando sua inserção num mundo que se configura por uma ordenação neoliberal. Para que se tenha uma ideia de como a educação corrobora a manutenção de tal sistema, muitos municípios brasileiros implantaram nas escolas públicas programas de empreendedorismo desde a Educação Infantil, como se vê em São José dos Campos (SP), Patrocínio (MG), Maringá (PR), Lucas do Rio Verde (MT), Rio do Sul (SC), Três Passos (RS), entre outros ${ }^{3}$.

Embora o exemplo acima seja reduzido diante da real dimensão do panorama, ainda assim ele nos propicia refletir sobre as tensões que ocorrem entre direitos e deveres como necessárias para a experiência educativa acontecer. Mas não podemos dizer que tais tensões são resultantes de um conflito de interesses entre as instituições família e escola, tampouco entre seus sujeitos. Ao contrário, tudo e todos estão unidos pela comunhão de valores, produzindo modos de viver e de subjetivação na experiência de um certo tipo de coletividade dominante.
3. As informações e detalhes dos programas nos municípios citados podem ser acessados nos sites das respectivas prefeituras. 
No sentido mais amplo da experiência de coletividade, os sujeitos desenvolvem seus modos de viver para se reconhecerem mutuamente pelas semelhanças, na busca por igualdade dentro dos parâmetros de uma determinada cultura, construindo comunidades e constituindo-se como um corpo coletivo e não como uma reunião de corpos indivíduos. Esse modo de estar e agir socialmente em nome de um coletivo põe em ação um sentido de heterogeneidade e alteridade, uma vez que coletivizar não é necessariamente massificar, ou criar uma identidade comum, mas encontrar interesses comuns em meio à diversidade, à pluralidade. Isso produz uma subjetividade de grupo em seu próprio acontecimento e ganha potência e fortalece a busca pelo bem-estar de um povo - o que implica responsabilidades e iniciativas micropolíticas, que podem ocorrer em instituições como escolas, associações, grêmios, organizações não governamentais e até por meio de macropolíticas ensejadas na esfera pública e governamental.

Paradoxalmente, quando esses mesmos princípios que constroem uma coletividade são articulados por uma perspectiva de política partidária, por uma cultura hegemônica de pequena ou de grande dimensão, podem gerar preconceitos e exclusão em relação a grupos e pessoas que não possuem as características específicas desejadas por um determinado coletivo, que não suportará as diferenças de hábitos, de crenças e de costumes do outro. 0 outro, o diferente, passa a ser, então, uma ameaça e precisa ser banido. Um claro exemplo disso é quando pessoas são discriminadas em razão de pertencimento a uma classe social ou por sua religiosidade, orientação sexual etc. Nesses casos de coletivização formada sob a manipulação partidária e hegemônica, a produção de subjetividade se dá por mecanismos muito distintos daqueles de um coletivo, que se faz em pluralidade.

Se considerarmos a educação como direito, na perspectiva de uma micropolítica que pensa a escola como lugar de uma coletividade constituída pela heterogenia e pela alteridade, no lugar de concebermos a criança como um indivíduo, como um projeto de vir a ser adulto, partimos da premissa de que a escola é o lugar de convívio entre diferentes - o que chamarei de modos de viver na experiência de pluralidade -, onde cada sujeito, em sua singularidade, encontra-se com o outro e, nesse encontro, engendra-se um modo de viver em coletividade que não é predeterminado por modelos culturais ou por grupos hegemônicos, visto se produzir na relação entre diferentes, na procura de estabelecer relações de equidade. 
Como Giorgio Agambem (2014) nos lembra, a infância não é uma etapa, mas uma condição da experiência humana, isso requer dos adultos conhecer a criança na auto-organização de suas aprendizagens, singularidade e potência, assim como, por parte da criança, conhecer os legados culturais refletidos na vida adulta. $\mathrm{Ou}$ seja, cada adulto e cada criança afirmando-se mutuamente como legítimo outro no convívio escolar (MATURANA, 2002), capazes de juntos e separadamente produzirem significados em encontros intersubjetivos com pessoas e com o mundo. 0 que se quer nesse contexto escolar, nas palavras de Carla Rinaldi, "é assegurar que os três sujeitos - crianças, educadores, pais - possam efetivamente habitar o espaço, mas, acima de tudo, garantir o bem-estar como criadores e usuários desse espaço e do que acontece ali." (RINALDI, 2012, p. 160).

Nessa concepção, não caberia aqui o exercício ético da educação hegemônica destinada àquela criança genérica e adultocêntrica, mas uma ética que deseja estar à altura da experiência do por fazer e do por pensar educação por implicações cruzadas, inventando-se em sua própria processualidade relacional, reunindo pessoalidades que estão dentro e fora da escola para, juntas, criarem inúmeros e possíveis modos de coparticipação em diálogo com questões educacionais, criando um estado democrático, por meio de uma ética do encontro ${ }^{4}$, que não concebe a diferença como um problema (no sentido negativo da palavra). Ao contrário, o outro é considerado como igual, mas na confirmação de não ser o mesmo, já que se trata de um encontro entre singularidades (DAHLBERG; MOSS; PENCE, 2003).

Para a Educação Infantil que tem por princípio ético o encontro, a experiência dialógica não ocorre apenas na interpessoalidade, mas também no confronto dos conhecimentos da pedagogia com tantas outras possíveis áreas, para gerar práticas inovadoras e disseminar experiências relacionais alternativas, dinamizando um constante movimento político de corresponsabilidade sócioconstrucionista da educação e da cultura da infância. Nas palavras de Carla Rinaldi,

\footnotetext{
projetar uma escola significa, essencialmente, criar um espaço de vida e de futuro. Isso requer pesquisa conjunta de pedagogia, arquitetura, sociologia e antropologia, disciplinas e campos de conhecimento que são convidados a expressar as próprias epistemologias e a comparar linguagens e sistemas simbólicos, com um novo tipo de liberdade, nascido do desejo de diálogo e de troca de ideias [...] Isso significa construir uma 'metáfora do conhecimento' que representa e sugere, ao mesmo tempo, mudanças e ações possíveis (RINALDI, 2012, p.150-151).
}

4. Dahlberg, Moss e Pence, no capítulo do livro Qualidade na educação infantil (2003, p. 56 61), fazem uma interessante síntese do pensamento de vários autores a respeito de uma ética do encontro. Mas é com a leitura de Emmanuel Levinas que nos aproximamos da relação entre adultos e crianças que se estabelece por meio da escuta entre diferentes "si" de uma experiência comum. 


\section{Investigar em conectividade para entender os modos de produção da experiência}

Independentemente dos modos pelos quais a escola se produz, conforme discutido acima, cada modo de viver, em suas distintas singularidades, produz seu próprio exercício ético, estético e político, fazendo com que todos estejam à altura daquilo que Ihes acontece, seja pela regulagem da aprendizagem da criança, para que ela alcance "sua" igualdade (coletividade homogênea, identitária), seja pela alteridade, que reconhece a criança como "outro" na experiência da equidade (coletividade heterogênea, o encontro entre singularidades).

Para um projeto educativo que procura pensar como se constituem as expectativas sociais e debatê-las publicamente à luz dos valores implicados na infância e na contemporaneidade, não caberia estipular a priori um consenso a fim de eliminar possíveis divergências entre dicotomias, tais como ensino formal e aprendizagem informal, família e escola, direitos e deveres, público e privado etc. 0 que se empreende, de fato, é um processo de dessubjetivação, ou seja, investigar para entender quais os modos de produção e os valores implicados na constituição dessa imagem social projetada de criança e, concomitantemente, quais os valores que poderiam configurar o olhar do adulto para o problema educação. Trata-se de desnudar o que aí está e, ao mesmo tempo, de desnudarmo-nos diante do que aí está. Estamos falando de viver um processo clínico da experiência e de seus sujeitos, numa análise sobre a singularização que se faz na pluralidade, na multiplicidade ${ }^{5}$, num conjunto de diferentes forças, fluxos e movimentos, em que os sujeitos modificam, modificam-se e são modificados.

É nesse sentido que o procedimento clínico pode acontecer, tornando-se imprescindível valorizar a experiência do encontro para, justamente nesse encontro, produzir estranhamentos e fricção entre diferentes pontos de vista, em busca de um plano comum - o que dá potência aos movimentos de transformação, no sentido da criação do novo, quando então se transcende o sujeito e o objeto da representação para dar lugar ao da criação. Parafraseando Marcel Duchamp, é dispor-se a criar uma educação inovadora que resulte do coeficiente da multiplicidade.

Marcel Duchamp, em seu texto 0 ato criador $^{6}$, enfatiza que, no embate em que o artista se encontra entre a intenção e a realização de sua obra, depara-se com uma "cadeia de reações totalmente subjetivas" (DUCHAMP, 2004, p. 73). Essa cadeia é o
5. A "multiplicidade" tem dois objetivos: 1. sublinhar os processos de movimento e de devir, em vez das noções estáticas de essência e de "ser", já-e-para-sempre constituído; 2. permitir pensar a diversidade e a variedade do mundo sem recorrer às noções tradicionais de uno e múltiplo. Um mundo constituído de multiplicidades é um mundo em movimento contínuo, um mundo de criações. Ver a este respeito Tomaz Tadeu (2002).

6. Texto originalmente apresentado à Convenção da Federação Americana de Artes, em Houston, Texas, USA, em abril de 1957. 
lugar intermediário ocupado pela tensão conflituosa que se dá por uma série de "esforços, sofrimentos, satisfações, recusas, decisões que também não podem e não devem ser totalmente conscientes, pelo menos no plano estético" (DUCHAMP, 2004, p. 73). A criação, que é a diferença revelada, só é possível pelo esforço do artista em querer que sua intenção se realize. Porém, Duchamp afirma que o que resulta desse processo advém do "coeficiente artístico pessoal, que é aquilo que se situa entre o que quis realizar e o que na verdade realizou [...] é como uma relação aritmética entre o que permanece inexpresso embora intencionado, e o que é expresso não intencionalmente" (DUCHAMP, 2004, p. 73) na obra.

0 fazer arte requer, por parte do artista, a intenção de movimentar-se por um processo inventivo dentro da imprevisibilidade do ato criador. Segundo Luigi Pareyson (1977, p. 32), a "arte não é somente executar, produzir, realizar, e o simples 'fazer' não basta para definir sua essência. A arte é também invenção [...] é um tal fazer que, enquanto faz, inventa o por fazer e o modo do fazer". Esse movimento, que não é linear e nem prescrito, provoca diferentes deslocamentos, desvios e bifurcações em um percurso. É preciso cartografar a paisagem que se inventa da fricção entre intenção e realização, entre afectos e perceptos de um devir arte.

Discutir conceitos que envolvem processo criador e cognição inventiva, por exemplo, pode propiciar interessantes conexões entre as experiências de um artista e de um educador, sujeitos de experiências, a princípio, distintas - e são, se considerarmos que uma experiência não depende da outra para existir. Porém, quando há um diálogo entre a arte e a educação dentro da escola, não para estabelecer um comparativo entre teorias pedagógicas e estéticas, com intuito na objetivação de definir uma metodologia do ensino da arte ou uma prática artística com fins pedagógicos, mas para criar aproximações subjetivas entre as experiências de artistar e de educar para gerar novas cartografias, então estamos falando de conectividade, para que uma paisagem educativa se constitua em seu por vir.

A cartografia, conceito apresentado por Gilles Deleuze e Félix Guattari na introdução de Mil platôs (1995), pode ser definida por um movimento de construir caminhos ao caminhar, fazendo do caminho e do caminhante-cartógrafo, deles e neles mesmos, o próprio traçado de possíveis percursos. Desse modo, processos de produção cartográfica acontecem por sua característica rizomática, qual seja, fazem-se em múltiplas direções, provocando 
deslocamentos e cruzamentos de linhas, construindo e conectando redes. Diante disso, cartografar uma nova paisagem educativa produz um movimento sócio-construcionista que advém de uma ética de um encontro que, por sua vez, advém de um ato cocriador e coinventivo.

Compartilho aqui o olhar de Virgínia Kastrup sobre a construção de rede em conectividade, que se desenha como tal por ser

\begin{abstract}
variável e flexível, sem extensão ou forma fixa, [...] faz-se e refaz-se pelas conexões que cada nó estabelece com sua vizinhança. Sua estrutura é multidimensional, no sentido que existem diversas séries heterogêneas encaixadas. Dito de outra forma, existem redes dentro da rede, ou ainda, cada nó pode abrir e constituir ele próprio uma rede. Enfim, a rede definese durante seu funcionamento, definindo posições que não são localizáveis nem previamente dadas. Por sua vez, o funcionamento não é linear e as conexões propagam-se por vizinhança em diversas direções, de maneira divergente ou bifurcante, atravessando diferentes dimensões por caminhos imprevisíveis (KASTRUP, 2007, p. 140).
\end{abstract}

Portanto, para que a rede em seu rizoma aconteça é imprescindível se deparar com a relação intersubjetiva de todos os envolvidos nesse processo, para confrontarem-se com o que não se sabe e sofrerem afecções diante das incertezas e imprevisibilidades do que está por vir, desprovendo-se do ilusório controle sobre o conhecido, para, no lugar, tomar emprestado o conhecido apenas como uma pré-forma para o que ainda não se formou, como um estágio ainda embrionário, em sua potencialidade plástica, para criar diferenças.

0 não confrontar, não ocupar-se de espaços intermediados resultantes de fricções, bem como eximir-se de debates, impede que novas paisagens educativas emerjam com toda a diversidade que elas possam conter e, ao mesmo tempo, que sejam constituídas por suas próprias ecologias. Quando o contrário acontece, dá-se, assim, uma paisagem de superfície acrílica com cores chapadas, onde nada adere e nada se conecta, a não ser ela nela mesma, onde objetos e pessoas são representações e representam-se nessa geografia asséptica que substitui o real para dar lugar à artificialidade da vida. Um terreno infértil, aplainado e com calçamentos lisos, definindo uma constância rítmica e balizadora para o caminhar, livrando-nos de qualquer acidente, desvios ou deslizes - um exemplo é a clássica capa criada nos anos 1970 para a cartilha Caminho Suave que é a fiel ilustração dessa tal paisagem. 


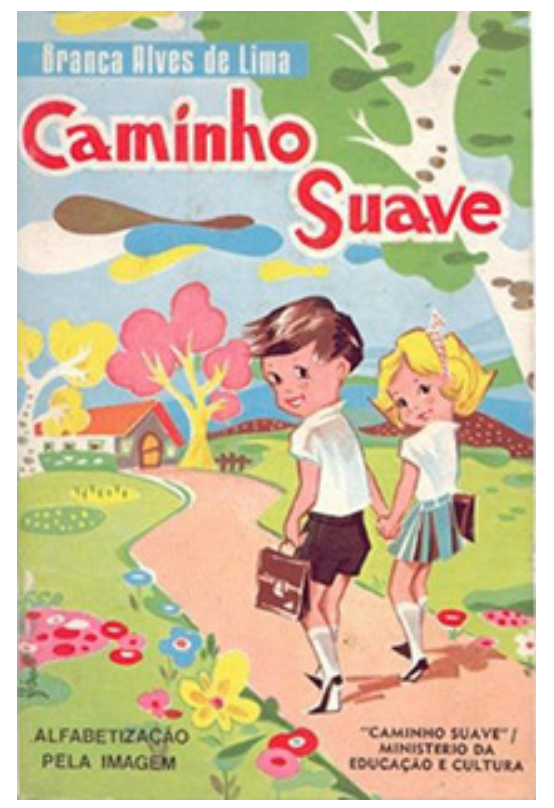

Figura 1 - Cartilha Caminho Suave

Fonte: internet

No território da educação que cria diferença, a paisagem se constitui a si mesma à medida que é constituída por um projeto que se dá fora dela, convocando os cartógrafos crianças e cartógrafos adultos, por serem eles os sujeitos da experiência educativa, cada qual com o seu passo, às vezes juntos, em outras, separados, para traçarem seus respectivos caminhos, demarcando lugares por onde passam distantemente uns dos outros, ou quando se cruzam passageiramente ou comungando demorados passeios; invadindo em bandos ruidosos os recantos antes escondidos, ou então os ocupando singularmente de modo silencioso e solitário. Em outras palavras, a escola se cria diferente pela presença dos diferentes adultos e crianças, mas só se percebem tais presenças diferenciadas quando se olha para elas desde um certo deslocamento.

A criança, numa atitude de cartógrafo, pode deslocar-se do conhecido e se ver no caminho "de seu aprendizado e da organização de sua experiência, de seu conhecimento e do significado dos seus relacionamentos com os outros" (RINALDI, 2012, p. 162). Nesse sentido, a mesma coisa poderá se dar com o adulto cartógrafo.

\section{Por uma formação autopoiética e rizomática}

0 educador que se predispõe a viver a incerteza da processualidade da aprendizagem em construção provavelmente 
despediu-se do desejo de se firmar na certeza do ensino programático construído, justamente para se encontrar no espaço vibracional como expansão da vida que se faz entre saberes instituídos e saberes constituídos pelos afetos, com um frágil (ou nenhum) contorno entre a utopia e o factível, o ordinário e o extraordinário. Esse estado caótico e incerto, ainda disforme e embrionário, permite deparar-se com a fonte de valores na própria vida e não no que se projeta dela, potencializando mudanças nos modos de produzir e se relacionar com valores que marcam o território cultural da educação formal. Eis aqui uma questão essencial para discutirmos: que formação é preciso para contar com educadores inquietos? Qual seria a formação profissional ideal para que esse projeto se realize na escola? Certamente não se daria por um caminho suave em que se segue uma ordem, um itinerário pronto para os caminhantes. Mas penso em algo muito próximo ao que Dewey diz esperar de um educador:

Nenhum problema surgirá a não ser que uma dada experiência conduza a um campo que não seja previamente conhecido que apresente novos problemas estimulando a reflexão (...) é parte da responsabilidade do educador prestar igual atenção em duas coisas: primeiro que os problemas surjam das condições das experiências que estão acontecendo no presente e que sejam decorrentes com as capacidades dos alunos; segundo que essas experiências despertem nos alunos a necessidade de busca ativa de informações e novas ideias (DEWEY, 2010, p. 82).

Essa disponibilidade atencional para observar aquilo que possa emergir da experiência e suas implicações relacionais (pessoais e com objetos) potencializa e orienta o educador-investigador a se situar como copartícipe das crianças de um sistema autopoiético e rizomático. Quer dizer, o sistema autopoiético define-se por se criar de si mesmo e em si mesmo. E rizomático, por ser aberto o suficiente para estabelecer conexões para além de seu próprio sistema e querer sofrer afecções (desvios, bifurcações) para continuar autocriando-se.

Num exercício hipotético, arrisco-me a enumerar os seguintes procedimentos que caberiam dentro de uma formação continuada para educadores disponíveis a viverem o sistema autopoiético e rizomático: (1) iniciar um debate público com a comunidade na intenção de saber quais valores pautam a concepção dos adultos perante a educação na primeira infância; (2) elaborar um levantamento com a equipe da escola para estipular quais daqueles valores seriam irrevogáveis, para todos vivenciá-los (adultos e crianças), e quais outros seriam acrescentados para fundamentar 
o trabalho; (3) discutir quais direitos implicariam crianças, pais e educadores e que seguramente a equipe defenderia em seu convívio social e nas ações pedagógicas; (4) buscar nas experiências de cada educador possíveis indícios de como coconstruir caminhos por fazer para a prática; (5) ter consciência de que esses caminhos por fazer precisam ser cartografados pelos próprios caminhantes, na experiência, cujo itinerário comum não é determinado a priori, mas se cria na convivência intersubjetiva e objetiva - um processo de constante projetação de interesses e desejos e suas coabitações numa mesma paisagem educativa, percebendo sua ecologia e de que modo ela se permite ser alterada diante da revisão de valores.

Todo o percurso que rapidamente esbocei pressupõe uma postura investigativa sobre a gênese da subjetividade constituída - que é a força reativa (que se mantém por um saber dominante e que podemos chamar de educação-caminho-suave) - e sobre novos modos de produzir subjetividade - força ativa (rizomaticamente dinamizada por um não saber curioso). Mas esse procedimento investigativo não significa dar as costas a um saber sabido, mas autorizar-se à crítica e ao diálogo entre o que está seguramente conhecido e o que seguramente não está conhecido, o que oportuniza lidar com as fricções que surgem diante da certeza/incerteza e da previsibilidade/imprevisibilidade, assim como num jogo de interações investigativas.

Ressalto que, no meu pequeno itinerário de formação, não caberia, para aquela suposta equipe, esperar se constituir primeiro como grupo de sujeitos da transformação, tampouco pesquisar modelos de mudança para a pré-elaboração de futuros planos de ação. São os próprios valores que precisam ser vividos em suas potências no corpo, nas atitudes e em contextos educativos conhecidos e não conhecidos - e que fazem com que os educadores percebam a experiência se configurando por si diante de diversificados agenciamentos que levam a um aprendizado complexo e aberto. Trata-se da educação poiética de uma pedagogia-agenciamento com e para além dos sujeitos.

Creio que para gerarmos ações transformadoras como educadores "inquietos" é preciso encontrar um senso de militância em e na coletividade, a fim de constituir a força que nos autoriza a sermos agenciadores de mudança num jogo de interação investigativa entre realidade e utopia, entre princípios e valores vigentes e aqueles desejados. E isso envolve uma postura crítica ao nos relacionarmos diretamente com a prática educativa exercida com crianças. Quero dizer com isso que se 
trata de sermos profissionais cidadãos desejosos de ir ao encontro da realidade e de confrontá-la com a utopia. Contrapomo-nos, assim, à ideia de transmissão de uma metodología de ensino que garanta o alcance de um resultado comum para todos, de uma objetividade consensual calcada em verdades envernizadas proferidas sob uma única perspectiva - a do adulto ensinador que consequentemente desconsidera os sujeitos da experiência e a configuração de uma coletividade pela reunião de diversidade. Para isso, precisamos lançar mão do exercício da "escuta atenta e sensível" ao que as crianças pensam e expressam em inúmeras e possíveis linguagens. Como Vea Vecchi sugere,

\begin{abstract}
basta escutar as crianças para entender que a transdiciplinaridade é um modo em que o pensamento humano conecta diferentes disciplinas (linguagens) com a finalidade de alcançar uma compreensão mais profunda de algo, não é uma teoria completamente independente da realidade nem um mandato docente; é uma estratégia natural do pensamento, respaldada por nossa hipótese inicial de que as oportunidades de combinação e criatividade em uma pluralidade de linguagens enriquece as percepções das crianças e intensifica suas relações com a realidade e a imaginação (VECCHI, 2013, p. 75, tradução minha).
\end{abstract}

\title{
Contextos abertos para aprendizagens abertas
}

Contexto aberto é um interessante recurso para se inaugurarem processos diversificados de aprendizagens também abertas para crianças e adultos. Trata-se de uma situação interventiva em que o educador prepara um ambiente e escolhe materiais propícios para que a criança tenha uma experiência de aprendizagem investigativa, na qual meninos e meninas possam levantar suas hipóteses diante do novo e confrontar suas teorias provisórias com objetos, adultos e entre colegas. Portanto, não se trata apenas de propor uma atividade planejada para atingir objetivos, ou uma sequência didática pré-agendada. Embora não signifique que os planejamentos sejam dispensáveis no contexto aberto, muito pelo contrário, é preciso ter um rigor nesse sentido, e o ato de planejar traz em seu foco no lugar da sequência - uma intencionalidade indagadora que se materializa em ambientação, de modo a propiciar os processos investigativos e as cartografias que fazem a experiência acontecer. 0 contexto aberto não quer produzir respostas, mas formular questões. Isso requer lançar mão da pedagogia da escuta, que coloca o adulto em um estado atencional para que possa "ouvir" com todos os seus sentidos, para além daquele da audição, o que propicia a escuta de emissões de ícones, símbolos e códigos presentes nas interações comunicantes e não necessariamente ditas. 
Para constituir esse contexto, o educador precisa partir de uma indagação que conecte com os valores da escola e que surja no interior de uma ou mais experiências vividas em grupo ou de modo singular. 0 que realmente importa é a qualidade da pergunta, que deve ser geradora de problematizações, provocando a movimentação para um processo investigativo - por exemplo, as crianças de um determinado grupo da escola passaram por uma experiência que despertou a curiosidade em saber como nascem as plantas. A questão, para o educador, não é formular perguntas para apreender a que resposta as crianças chegarão, mas viver uma experiência indagadora pós-figurada, quer dizer, uma experiência que cria seu próprio modo de existir e não se configura por antecipações representacionais, mas pelo florescer das relações possíveis estabelecidas em lugares nunca antes cultivados.

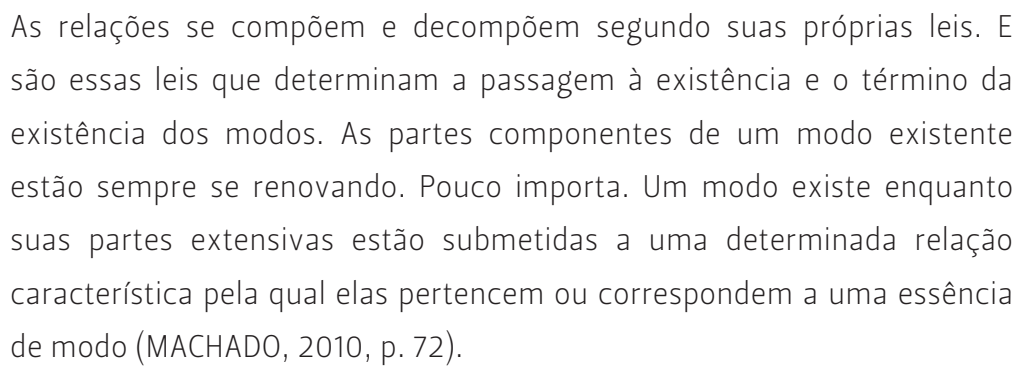

O território de uma experiência pós-figurada acontece enquanto se vive a experiência - o prefixo "pós" quer dizer uma figuração nunca antes pensada, não previsível, uma abertura para o por vir. E se, ao contrário, a proposta é viver num território de experiência pré-figurada, o mapa já está dado, não havendo muitas possibilidades de fuga para novas aprendizagens, de invenção para novos caminhos, ou do que pode advir para além do lugar de chegada previsível. Por isso o território das experiências pós-figuradas precisa ainda ser cartografado. E são os diferentes pontos de vista que o cartografam enquanto vivem o fluxo da experiência.

Se dentro dos valores que a escola elege está a coconstrução dos processos de aprendizagem, então cabe ao educador propiciar contextos que oportunizem a vivência desses valores, sem esquecer o assunto de interesse das crianças. Ou seja, o educador não estará lá promovendo experiências pré-figuradas para se relacionar com crianças respondedoras de suas perguntas ou dos saberes conhecidos. Tampouco dirigirá a cena, encaminhando o grupo pelo caminho suave de uma sequência didática que artificializa a coconstrução. É preciso entender que o educador também estará participando da experiência, intervindo para 
que, juntos - ele e as crianças -, inventem modos para que a processualidade da aprendizagem coconstruída se realize numa experiência pós-figurada.

Essa presença do adulto está muito distante daquele que se coloca no mesmo lugar das crianças. A ideia é interrogar-se sobre que tipo de agenciamentos se estabelecem no encontro entre o ponto de vista do adulto e o ponto de vista da criança numa mesma experiência, sem que ninguém abra mão de sua singularidade. É dar espaço para que o ponto de vista do outro ganhe visibilidade e possibilite estabelecer intercessões, gerando multiplicidades em conectividades (DELEUZE, 2013).

Entendo que essa postura de educador requer dispor-se a ser afetado pela imprevisibilidade e incerteza daquilo que possa emergir do próprio movimento relacional, comprometendo-se com a sua investigação na intenção de realizar uma autoformação, e também para que possa contribuir com seus pares na coconstrução da experiência educativa, que se faz por intercessões e conectividade, implicada pedagogicamente com a aprendizagem em seu próprio devir - é a experiência em si: ela, vida.

\section{REFERÊNCIAS}

AGAMBEN, Giorgio. Infância e história: destruição da experiência e origem da história. Traduzido por Henrique Burigo. 3. ed. Belo Horizonte: UFMG, 2014. 186 p.

DAHLBERG, Gunilla; MOSS, Peter; PENCE, Alan. Qualidade na educação infantil: perspectivas pós-modernas. Traduzido por Magda França Lopes. Porto Alegre: Artmed, 2003. 264 p.

DELEUZE, Gilles. Conversações. Tradução de Peter P. Pelbart. 3. ed. São Paulo: Ed. 34, 2013. 240 p. (Col. Trans)

DELEUZE, Gilles; GUATTARI, Felix. Mil platôs - Capitalismo e esquizofrenia, vol.1. Tradução Ana Lúcia de Oliveira, Aurélio Guerra Neto e Célia Pinto Costa. São Paulo: Ed. 34, 1995. 128 p. (Col. Trans)

DEWEY, John. Experiência e educação. Traduzido por Renata Gaspar. Petrópolis, RJ: Vozes, 2010. 165 p. 
DUCHAMP, Marcel. 0 ato criador. In: BATTCOCK, Gregory. A Nova Arte. São Paulo. Perspectiva: 2004.288 p., il. p.b.

KASTRUP, Virgínia. A invenção de si e do mundo. São Paulo: Autêntica, 2007. 253 p.

MACHADO, Roberto. Deleuze, a arte e a filosofia. 2. ed. Rio de Janeiro: Zahar, 2010. 340 p.

PASSOS, Eduardo; KASTRUP, Virgínia; ESCÓSSIA, Liliana (Orgs.). Pistas do método cartográfico: pesquisa-intervenção e produção de subjetividade. $3^{\text {a }}$ ed. Porto Alegre: Sulina, 2009. 207 p.

PASSOS, Eduardo; KASTRUP, Virgínia; TEDESCO, Silvia (Orgs.). Pistas do método cartográfico: a experiência da pesquisa e o plano comum - vol. 2. Porto Alegre: Sulina, 2014. 310 p.

PAREYSON, Luigi. Os problemas da estética. 3. ed. Traduzido por Maria Helena Nery Garcez. São Paulo: Martins Fontes, 1997. 246 p.

RINALDI, Carla. Diálogos com Reggio Emilia - escutar, investigar e aprender. Traduzido por Vânia Cury. São Paulo: Paz e Terra, 2012. 397 p.

SOUZA, Renato R. O que é realmente virtual? Revista de Informação e tecnologia, Campinas, [s.n.], [s.p.], abr. 2001. Disponível em: <http://www.ccuec.unicamp.br/revista/ infotec/artigos/renato.html>. Acesso em: 10 nov. 2015.

TADEU, Tomaz. Tinha horror a tudo que apequenava... Biografia intelectual. Revista Educação, Especial Deleuze pensa a Educação, São Paulo, ano II, n. 6, p. 06-15, maio/jul. 2002.

VECCHI, Vea. Arte y creatividad en Reggio Emilia - el papel de los talleres y sus posibilidades en educación infantil. Madrid: Morata, 2013. 300 p.

Recebido em: 15/10/2015

Revisto em: 30/11/2015

Aceito em: 03/12/2015

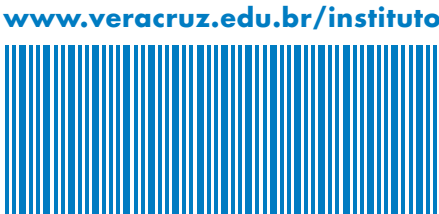

